cident five weeks since, by which he ruptured his urethra: it was followed by an abscess, and almost entire closure of the canal. Mr. Skey, after some difficulty, succeeded in perfecting the communication of the soparated portions of the tube. The operation occupied twenty-five minutes, during the whole of which time the patient was insensible to pain. I need scarcely observe, that he inhaled the vapour, at intervals, during the whole time; and before being taken out of the theatre, exclaimed to the question, "Have you suffered pain?" "No; he put something into my mouth which sent me to sleep!" I may here add, that the patient is doing well.-I remain, Sir, your obedient servant,

st. Bartholomew's Hospital,

S. J. TrACY. January, 1847.

N.B.-The apparatus described was manufactured by $\mathbf{M r}$. D. Ferguson, instrument-maker to the hospital.

\section{RENIOVAL OF A TUMOUR}

By Joins Charles Hali, M.D., M.R.C.S., East Retford.

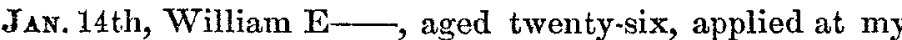
house for the purpose of having a small fatty tumour, about the size of an egg, removed from his neck. Mr. Cocking, one of the medical officers of the Hull Dispensary, was present during the operation. The man was placed in an arm-chair, and the vapour applied by means of an instrument. which was supplied to me by Mr. Hooper, the operative chemist, and is the one figured in Tre LANCET of last week, and is certainly very complete, and well adapted for the purpose. He complained, at the first, of a slight tickling sensation in the throat: this soon went off; in two minutes, the pulse had risen to 135 ; in another minute, his arm was slightly raised; his feet were then extended, and he fell back in his chair in a complete state of insensibility. The tumour, being somewhat adherent, required a good deal of dissection to separate it from the surrounding parts. The operation occupied about three minutes; and in about another minute, the man awoke, declaring he had "felt no pain"" and it took some little time to convince him the operation had been performed. During the operation, he raised the leg once, but said he had felt no pain at all: he had been in a dream.

There is a class of cases in which the vapour has not yet been tried; and from my experience in one case, $I$ am led to recommend it with confidence to the members of my profession. I allude to retention of urine from spasmodic stricture of the urethra: in such cases it will, I think, be found an effectual and elegant substitute for the warm bath, opium, bleeding - the whole paraphernalia of the former plan of treatment. In the case to which I allude, all attempts to pass a catheter were useless. On applying the vapour, the patient passed into a state of insensibility in five minutes; and during his dreamy unconscfousness, a catheter was passed without any pain, the bladder emptied, and on coming round, he got up perfectly free from pain, although previously in the greatest agony from an overloaded bladder. I have every reason for thinking the application of the ether vapour will be attended with the greatest possible benefit to those unhappy patients who may be suffering from the torments unrelieved retention of urine causes, and have therefore embraced the earliest opportunity of making the result of my experience known to the profession. We all know the difficulty of passing a catheter in these cases-a difficulty which I hope will now, in the majority of them, be removed.

Grove-street, East Retford, Jan, 1847.

\section{THE OPERATION FOR PTOSIS.}

To the Editor of THe LANCET.

Sir,-Some years ago, I performed the operation for ptosis, described by Dr. Brett in your last number; but resolved never to have recourse to it again, should similar cases present themselves to my notice. My patient was in a much worse predicament after than before the operation, in consequence of the want of protection to the ball of the eye from dust, flies, \&c., the intolerable annoyance of which is infinitely greater than the evil of a closed eyelid. My patient never forgave me.-I am, Sir, yours,

C. R. BREE.

Stowmal ket, Dec. 1847 .

* The first evening $\mathrm{I}$ received the instrument from Mr. Hooper, not having a patient to practise upon, and wishing to try the effects of the vapour, applied the tube to my own mouth. I had not tried it long, before I f back in my chair, and remained in a dreany state for some little time. When 1 awoke, $I$ was not for a moment aware of what had taken place, phil the sight of the instrment recalled it to

\section{PATENT HUMANITY.}

To the Editor of Tine Lanoet.

Sin,-I am a constant reader of The Larret, in conmon, as I believe, with many other members of the bar. As your reader, $I$ could not but take considerable interest in the new application of ether for the purpose of procuring insensibility during surgical operations; and as a lawyer, my attention has been equally arrested by the attempt which scems to be making to degrade a noble discovery to the level of a quack medicine. I agree with you, that a testimonial is due to the discoverer; but let us distinguish between the discoverer and the speculator, and let the interests of humanity and the claims of genins walk hand in hand. It is the duty of the pliysicians and surgeons of our public hospitals to vindicate both; and it is your province not to snffer either question to die.

But, with regard to the patent, it is said, on the one hand, that the discovery is not susceptible of such a thing; and, on the other, that no one can tell whether the patent can be sustained or not, until the specification, not yet lodged, has been examined. Nor, I may add, can there be any proceeding for sustaining the patent, until that specification be lodged: in fact, there is no patent until then. But although it be very true that, with regard to the specific letters in question, no opinion could now be adventured on whether they could be supported or not, it is equally true that, for all the purposes of the argument, enough exists in the patent law itself to warrant the decided opinion, that no extent of legal ingenuity could frame a specification which could prevent a medical man from procuring insensibility by administering ether, or from cutting off a leg or an arm, or performing any other surgical operation during such insensibility.

We need not go, although they are not unimportant to the question, to the general conditions, subject to which all patents are granted, to prevent their abuse, in proof of this; for the direct condition is decisive of the point. The patent must be in respect of a manufacture, as that mannfacture must be new. You cannot have a patent of a principle; you cannot have a patent of a result, except with reference to the material mode by which it is brought about; for materiality is still more an essential condition than absolute novelty. In fact, a patent can only be obtained in respect of a process or an apparatus; the vendible result is but the accidental or tangible representation of the thing: the patent itself is in respect of the novelty of the material, or of the novelty of the combination or process by which that vendible result is produced.

Now there is no pretext for saying that a patent can be taken out for cutting off legs whilst the patient is in a state of insensibility, or the mesmeric quacks might patent their manual flourishes and passes; nor could a patent be obtained for the mere administering of ether, for that is common, both as a medicine and a toy. Can there, then, be a patent for administering ether by inhalation, so as to produce insensibility? Can you patent the administration of jalap till a given effect is produced on the bowels? That is the reductio ad absurdam to which we are driven. Take the highest ground, and say that the effect is to be produced invariably by a given fixed quantity; you might as well try to patent a definite number of grains of rhubarb; or a publican might as well try to patent a certain proportion of Gordon's gin to a definite quantity of hot water and sugar, and call it a patent inebriator. But the question need not be argued so high as that: the inhalatiou must vary with the constitution of the patient; and the adminis. tration itself must be a matter of skill in the hands of those employing it. That is decisive of the question. The discovery is, that insensibility can be produced by a lnown medicine, so to call it, administered, by a known process, up to a certain point; that is an accidental fact, of great valne, certainly, but it is not a vendible result. If, indeed, the discoverer has any novel method of generating the gas, or any novel apparatus for administering it, both may be patented; but it will be open to the faculty to employ every other method, whether now known and generally usch, or which may be hereafter contrived by the application of their abundant scientific knowledge, and of the mechanical skinll of the many able men who construct instruments for the medical profession. I am Sir, your obedient servant,

Smith-square, Westminster, Jan. 1837.

J. B. Kincton.

"Medicine has for centuries served as the prop to natural science-a benefit which the latter has repaid by making the other feel its superiority."-Professor Marx. 